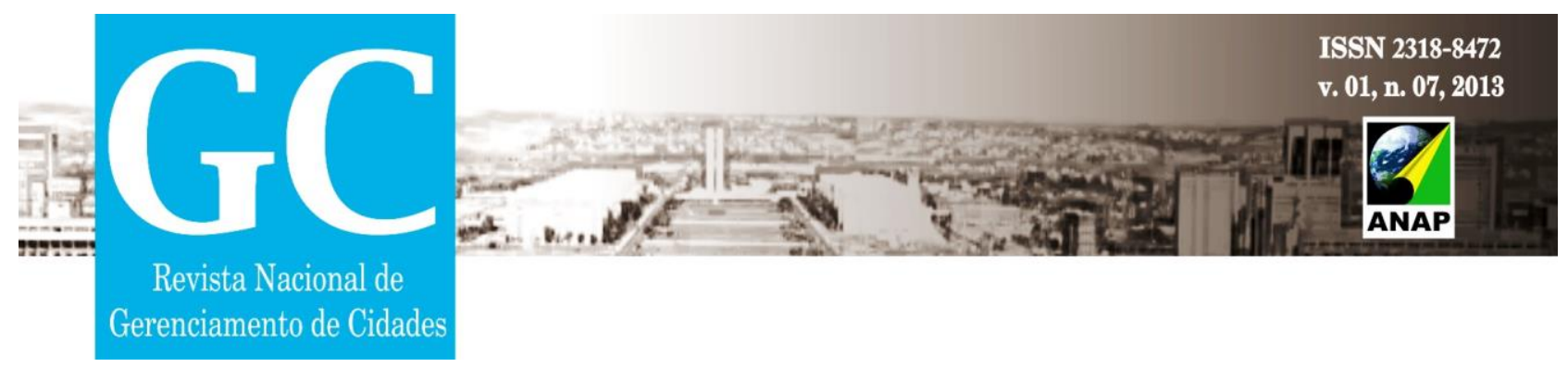

\title{
ARQUITETURA E PODER: BRASÍLIA E SERRA DO NAVIO NA AMAZÔNIA
}

\author{
José Alberto Tostes
}

Resumo: Este trabalho tem como finalidade realizar uma análise comparativa entre as cidades de Serra do Navio e Brasília, ambas foram idealizadas e construídas para atender um propósito especifico. Os princípios entre as duas cidades, vão além das diferenças de escala, estão guardadas na própria concepção do espaço moderno. O suporte de discussão teórica está na concepção de Brasília tida como cidade moderna formalista e Serra do Navio uma cidade moderna adaptada à selva com características naturalistas ou cidade jardim moderna. O ambiente onde está situado Brasília é o cerrado brasileiro com clima ameno e poucas oscilações de chuva e com um inverno pouco rigoroso. Serra do Navio foi à primeira experiência de uma cidade modernista na Amazônia, sob a tutela de uma empresa mineradora industrial na Região. Nesta pesquisa, optou-se em aplicar o método comparativo, se trata de aferir realidades distintas. A relevância deste trabalho está na formatação do projeto moderno no Brasil, capaz de se adaptar às condições morfológicas, climáticas e culturais bastante adversas, em ambos os projetos.

Palavras-Chave: Cidade moderna. Brasília. Serra do Navio.

BRASÍLIA E SERRA DO NAVIO 


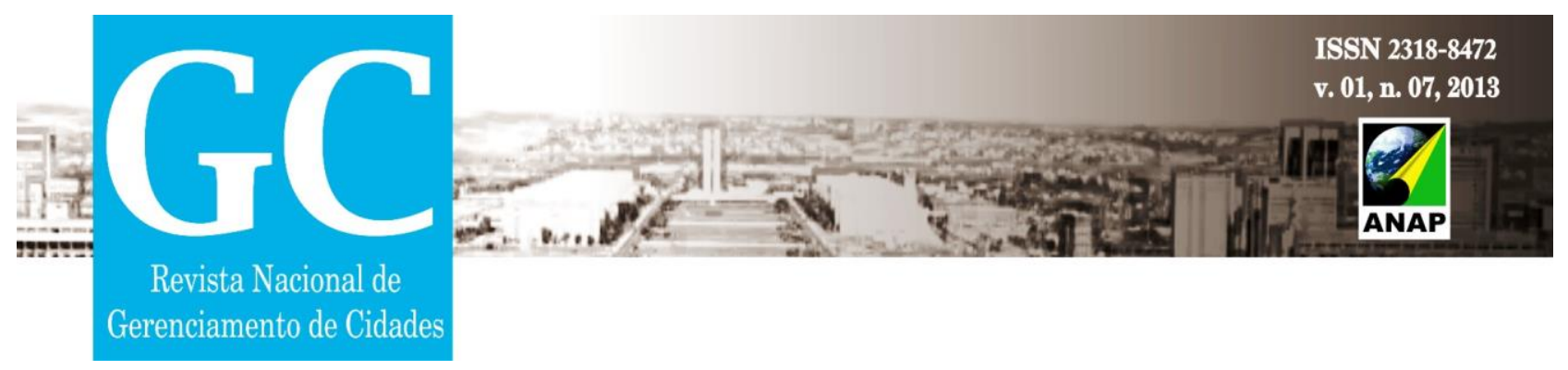

Um pouco mais de cinquenta anos, um gigantesco canteiro de obras iria dar lugar a uma das maiores referências da arquitetura internacional. Segundo Schlee \& Ficher (2010) Brasília estava prestes a ser concluída. A obra começou no ano de 1955, a primeira obra foi o campo de aviação (denominado de Vera Cruz), entre os anos de1956/57, foi selecionado o projeto urbanístico da nova capital, e da execução do plano, decorreram apenas quatro anos e oito meses. Transferir uma capital não era novidade. Tampouco construir cidades praticamente do nada, exnihilo. Algo já experimentado no Brasil, mas nunca com tanta intensidade (e expectativa!). De acordo com Schlee \& Ficher, uma rápida análise das fotografias que registraram o festivo dia 21 de abril de 1960, permite constatar uma Praça dos Três Poderes inacabada, um palácio das Relações Exteriores inexistente, uma catedral em osso e um teatro interrompido. Mesmo assim, o sonho tornou-se realidade. E a realidade, um fato cotidiano.

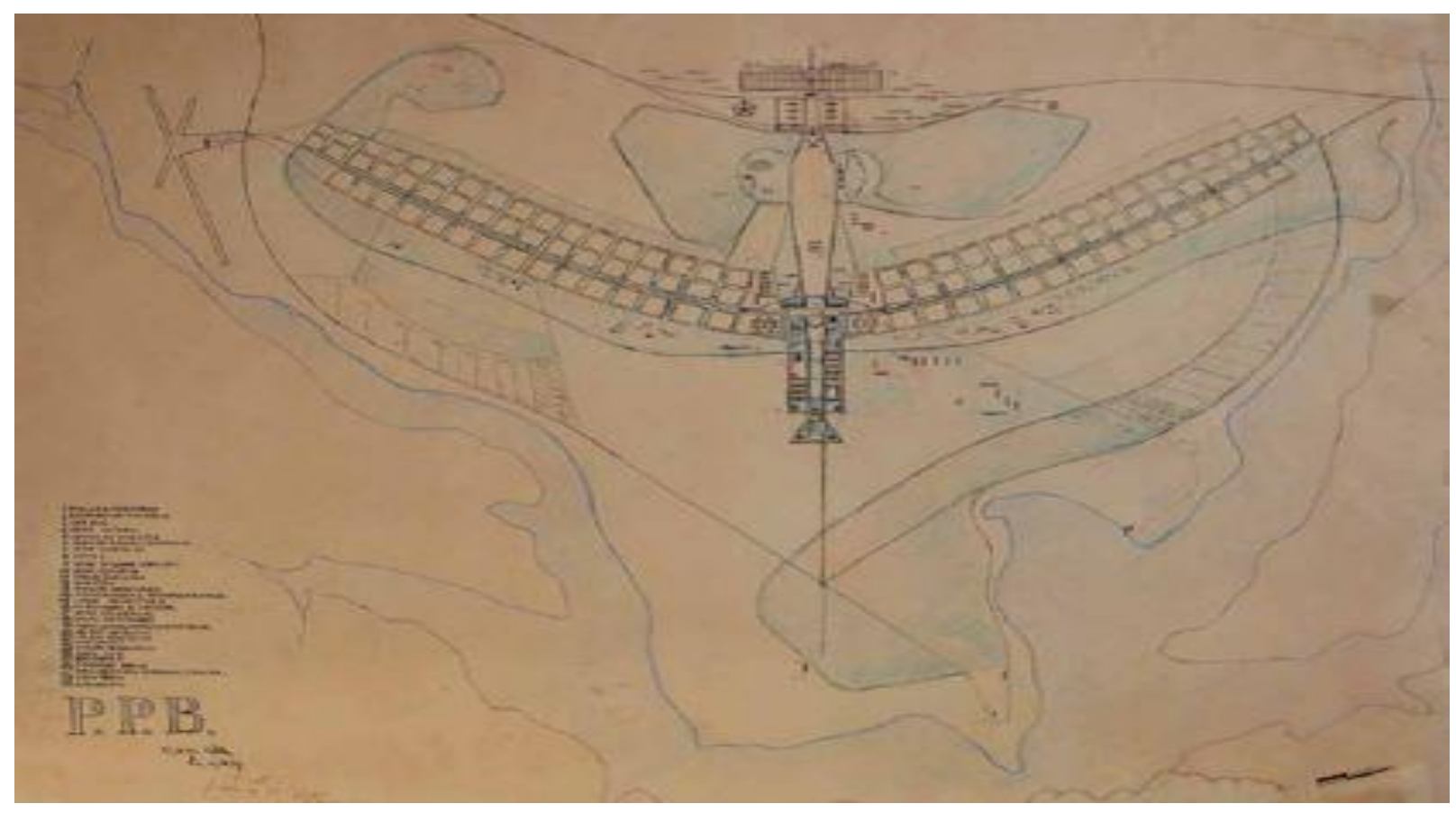

Fig. 01. Esquema do Plano Piloto na cidade de Brasília.

Fonte: Brasília-1960-2010. 


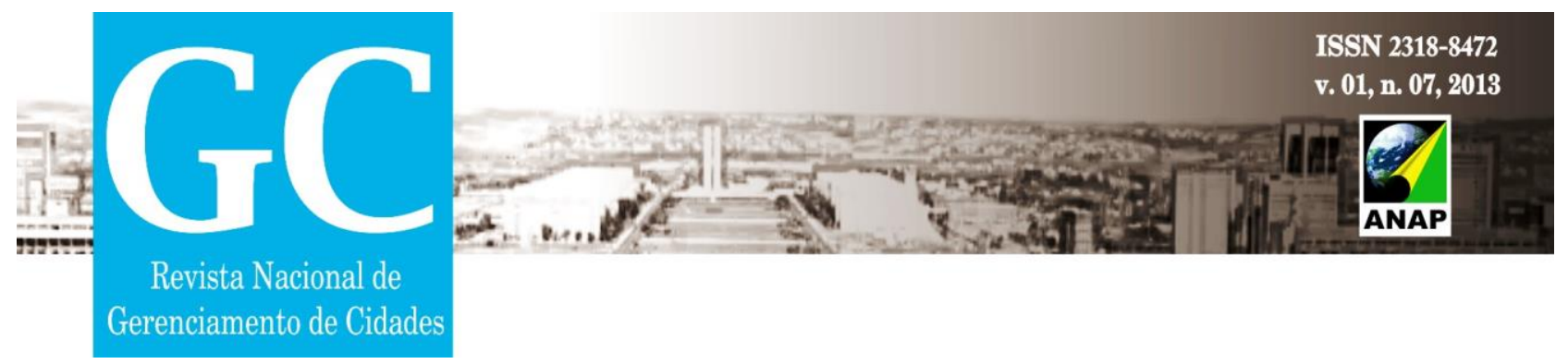

De acordo com Schlee \& Ficher (2010), o Plano Piloto de Lucio Costa é apenas uma entre as trinta regiões administrativas locais. A cidade descentralizou-se, o Distrito Federal metropolizou-se, e a região conurbanizou-se. A cidade sugerida, sonhada, imaginada, desenhada, riscada - criada, como dizia Lucio Costa - tornou-se real (fig.01). E a utopia, aqui encarada como a "vitória do desejo", transformou-se em um fato concreto. Segundo Schlee \& Ficher no prefácio do livro: Brasília- Cidade Moderna, cidade eterna descreve assim:

\begin{abstract}
Brasília pode ser vista como arquitetura e sobre ela podemos construir novos discursos (ou reforçar antigos...). Em Brasília - cidade moderna, cidade eterna, Frederico de Holanda faz tudo isso (e muito mais...). O autor segue o caminho inicialmente trilhado no seu importante O Espaço de Exceção (1997 e 2002). No entanto, vai além. Integralmente dedicado a Brasília, o livro explora as duas visadas acima citadas: a cidade como arquitetura e o que se tem dito sobre ela; $\mathrm{e}$ organiza-se em três tempos, o da criação, o da constatação e o da projeção/ desejo (passado, presente e futuro). Ou, como a cidade foi pensada por Lucio Costa, como Brasília se encontra na atualidade ("a verdade objetiva dos fatos") e quais as perspectivas utópicas para a capital do país (SCHEE \& Ficher, 2010).
\end{abstract}

Paralelo à construção de Brasília, outro projeto de menor escala, mas também de grande envergadura na Amazônia era inaugurado, a Vila de Serra do Navio, iniciava-se um marco histórico para o então Território Federal do Amapá, posteriormente estado do Amapá, esta época, é até hoje configurada de sentimentos que se contrastam ao longo de mais de 05 décadas após a construção desta Vila. A Vila de Serra do Navio se tornou um mito porque representou e representa o símbolo de ostentação de riqueza e austeridade, da qualidade vida vivida por seus moradores, e acima tudo demarca a própria história do Amapá. 

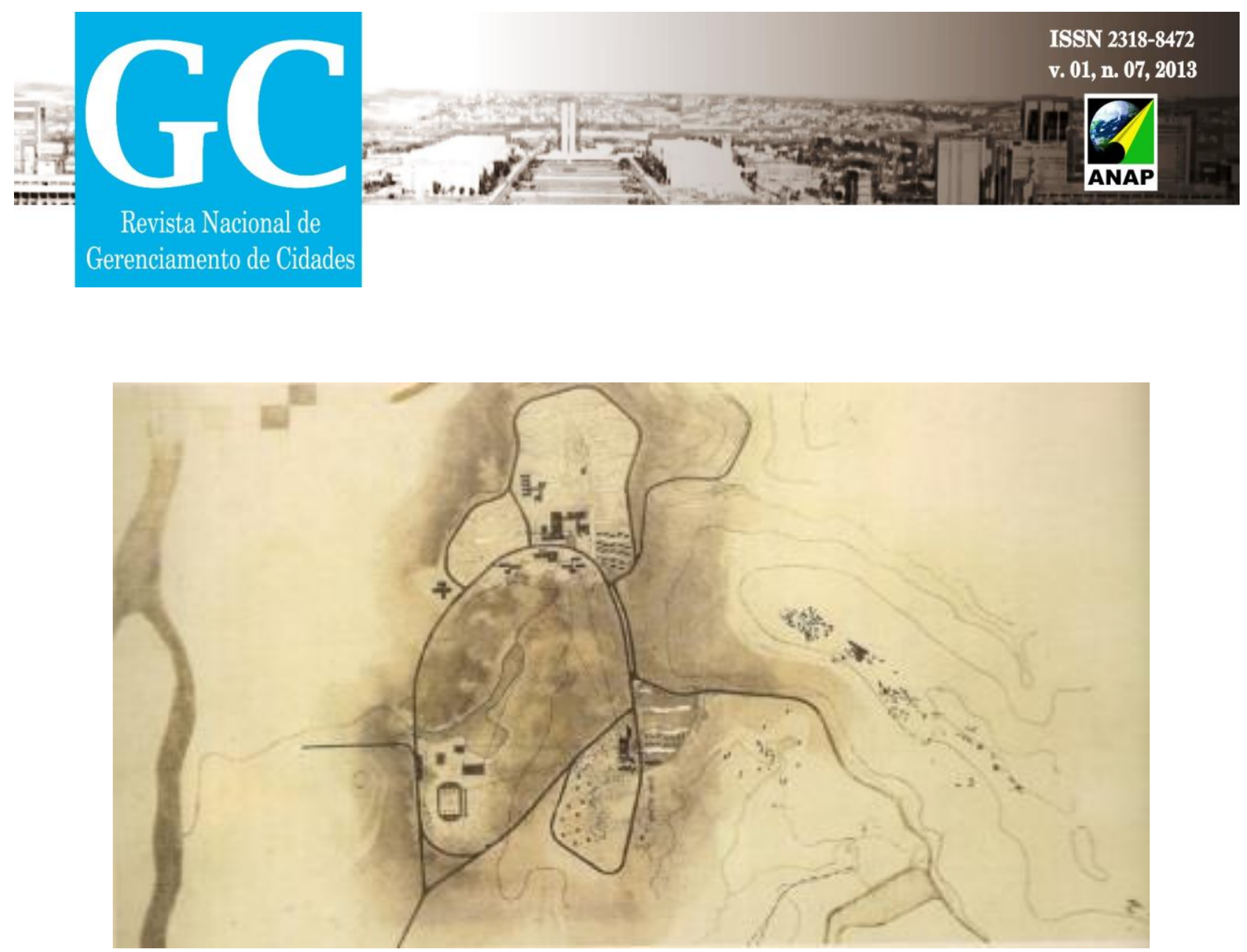

Fig. 02. Esquema original do desenho urbano da Vila de Serra do Navio.

Fonte: Segawa, 1997.

As ideias que permearam a criação e implantação da cidade de Serra do Navio foram cercadas de todos os cuidados necessários em relação aos preceitos básicos que auxiliaram a realização e materialização do projeto principalmente em relação às condições locais, fatores climáticos, culturais como hábitos e costumes do caboclo amazônida foram determinantes para o tipo de cidade e de arquitetura planejada para o local (fig.02). Deve-se ressaltar que esta nova cidade foi pensada exatamente no interior da selva o que dificultava ainda mais as condições de adequação a realidade do lugar, bem como as características físicas. As circunstâncias técnicas e os cuidados por parte da equipe envolvida possibilitou compreender a dinâmica do lugar. A Vila de Serra do Navio foi construída com todos os requisitos importantes e que fizeram deste empreendimento uma das grandes referências nacionais, e até mesmo internacionais, pelas adversidades encontradas para a execução.

Segundo Ribeiro (1992), tratando-se de Serra do Navio no ano de 1955. Como resultado o resto da Amazônia, a região era quase desabitada; exceto por raras famílias 


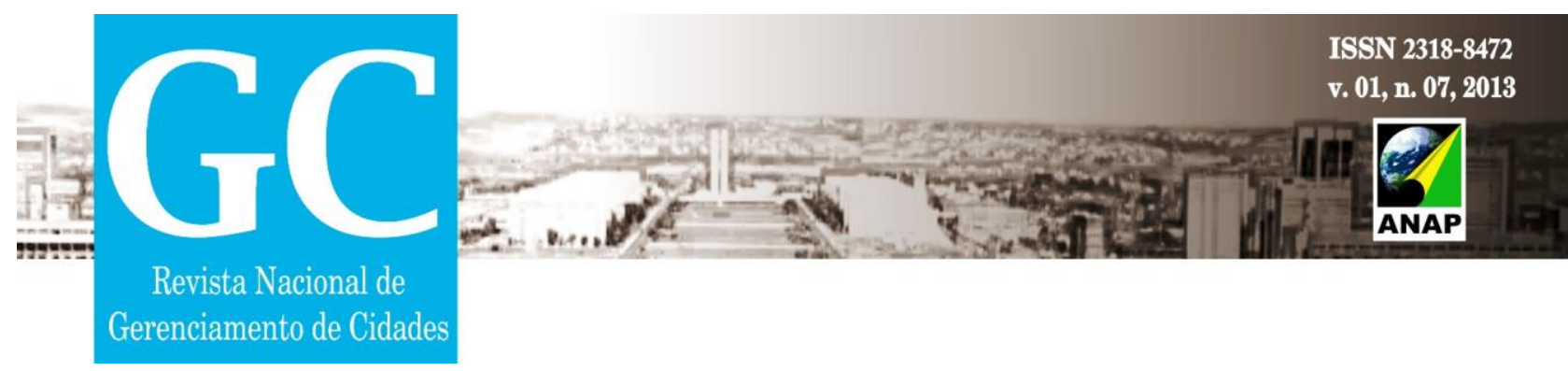

de caboclos, alojadas em ranchos de madeira erguidos à beira do rio, apoiados sobre palafitas e cobertos de sapê. Ou por garimpeiros de ouro, aventureiros que se deslocavam de uma região para outra, acampando aqui e ali. Nem índios havia mais por lá; tendo desaparecido os poucos que existiam.

No projeto da Vila de Serra do Navio, o arquiteto manteve sempre um olho atento ao custo de execução, e o outro, aos futuros custo de operação e manutenção. O que explica certos detalhes do plano e dos projetos, que à primeira vista podem parecer exagerados para as condições brasileiras. Em urbanismo, o conceito de manutenção é mais abrangente do que em arquitetura. Sabe-se, por exemplo, que na implantação de qualquer núcleo urbano alguns itens de infra-estrutura são muito onerosos. É o caso da distribuição de água potável e do tratamento de esgotos - daquilo que é usualmente chamado o saneamento básico foram estudados com muito cuidado, e corretamente resolvidos.

Todavia, exatamente por se tratar de uma cidade fechada, além de estar geograficamente isolada, atenção especial foi dedicada à listagem e ao dimensionamento dos equipamentos comerciais, bem como das inúmeras modalidades de serviços que deveriam ser colocados à disposição dos futuros moradores. Exemplificando, era preciso saber, conhecidos os hábitos e níveis de renda de uma população estimada em 2.500 pessoas.

$\mathrm{Na}$ Serra do Navio, tratando-se de um núcleo residencial a ser planejado desde o seu início, Bratke teve a oportunidade de escolher a localização mais favorável do sítio urbano, entre várias alternativas possíveis. Uma área de 2.500 há era reservada à mineração e outra de 2.300 ha para a implantação de infra-estrutura industrial e social. Pelos resultados do pré-dimensionamento, a vila ocuparia uns 100 hectares. Bratke dispunha de levantamento aerofotogramétrico da região, com hidrografia, relevo e cobertura vegetal; contava ainda com o conhecimento visual da área, resultado de sua visita local. 


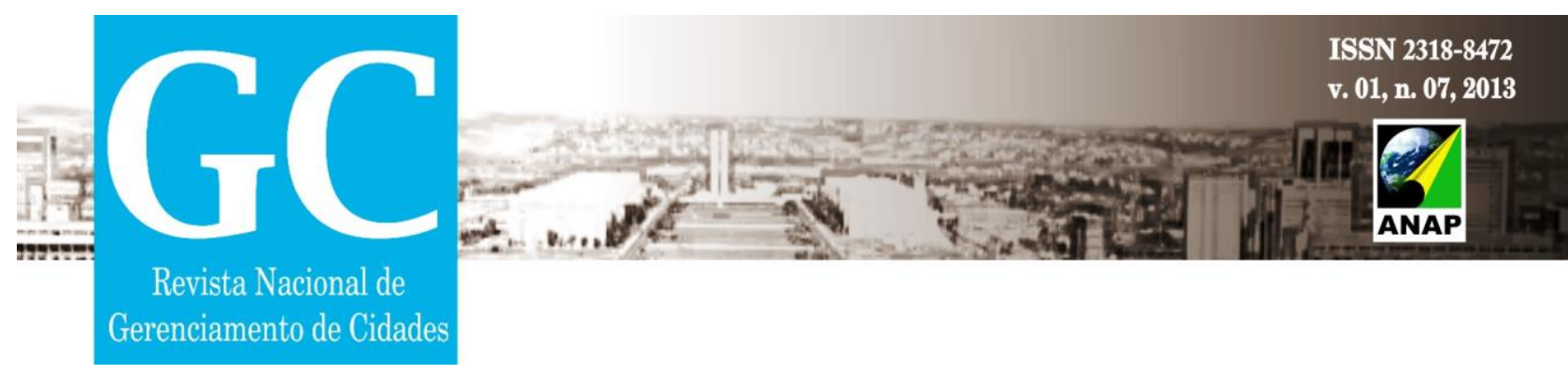

Dos 2.500 hectares de terra da concessão, a maior parte correspondia às jazidas de minério; e, para a construção da Vila, não poderiam ser utilizados terrenos alagadiços, nem áreas distantes da estação terminal da estrada de ferro. De início foi considerada uma área plana, não inundável, situada próxima ao rio Amapari. Logo se verificou que, naquele local, ocorria acumulação de neblina quase diariamente, no período da manhã, que se dissipava apenas por volta do meio dia; não era, portanto, uma localização favorável. Bratke se decidiu por duas elevações suaves afastadas do rio, separadas entre si por um pequeno vale. $O$ local era próximo à estação ferroviária; por ser mais alto que o entorno, gozava de boa ventilação e oferecia alguma visão da paisagem. Cumpria agora desenvolver os estudos de ordenação física desse espaço territorial.

As concepções sobre a Vila de Serra do Navio deixam claro que este foi sem dúvida um grande empreendimento, não somente a concepção urbanística e arquitetônica, mas a possibilidade de se pensar a integração de todo o conjunto com o meio existente, vale lembrar que muito antes da materialização do projeto de Serra. Oswaldo Bratke visitou outras regiões semelhantes e se convenceu da necessidade de adequar para as condições especificas de Serra do Navio. Para Bratke os conjuntos urbanos pensados para este tipo de projeto afluem pessoas de diferentes regiões, com diferentes costumes e variada formação cultural. Para compatibilizar tão diferentes camadas da população, permitindo uma vida harmoniosa em sociedade.

\section{AS COMPARAÇÕES ENTRE SERRA DO NAVIO E BRASÍLIA}

Comparar as duas cidades, vai além da diferença que existe na escala, outras estão guardadas na própria concepção do espaço moderno, onde uma é tida como cidade moderna formalista e a outra como cidade moderna naturalista ou cidade jardim moderna. O motivo de tal empenho se configura na necessidade de entender como o modernismo se instalou no Brasil em duas realidades distintas no que se refere ao perfil da população, 


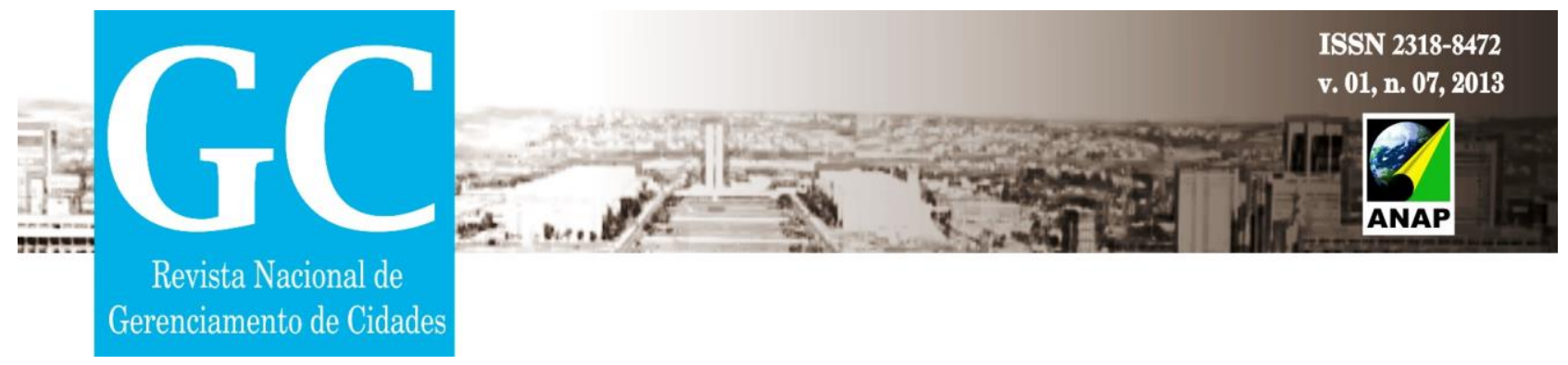

ao clima e aos motivos que impulsionaram esses projetos. Brasília o espaço da monumentalidade (fig.03).

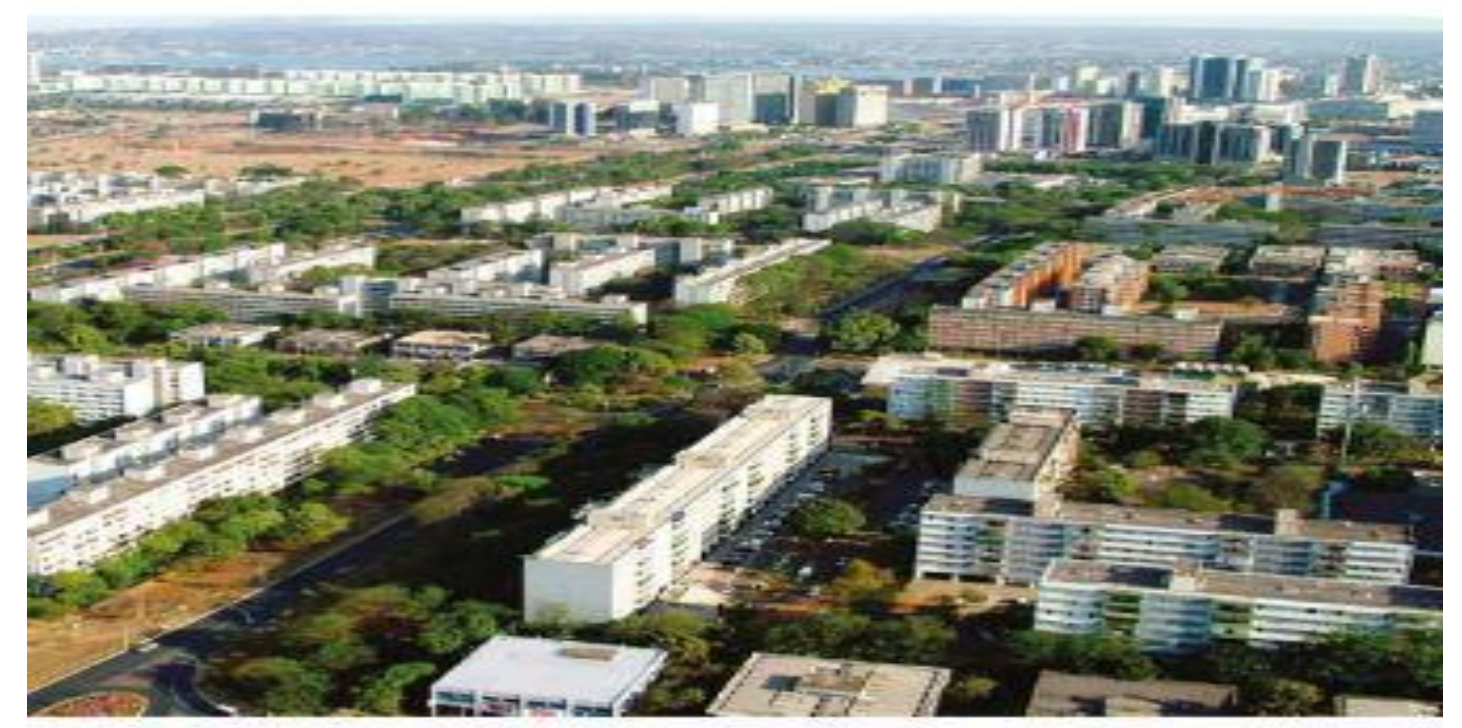

Fig. 03. Vista aérea da cidade de Brasília.

Fonte: Brasília 1960-2010.

Brasília e Serra do Navio são um marco na história, preservando as proporcionalidades, Brasília segundo Tostes (2011):

Distanciada dos grandes centros e centrada nas figuras expoentes do Presidente Juscelino Kubistchek e dos arquitetos Oscar Niemayer e Lúcio Costa, criadores dos espaços públicos e arquitetônicos. Brasília é uma das maiores referências de cidades planejadas no mundo, um laboratório a céu aberto para os profissionais que estudam o espaço urbano planejado. (JORNAL TRIBUNA AMAPAENSE, 2011).

Serra do Navio foi à primeira experiência de uma cidade modernista na Amazônia fruto da "primeira experiência de mineração industrial na Amazônia" (DRUMMOND \& 


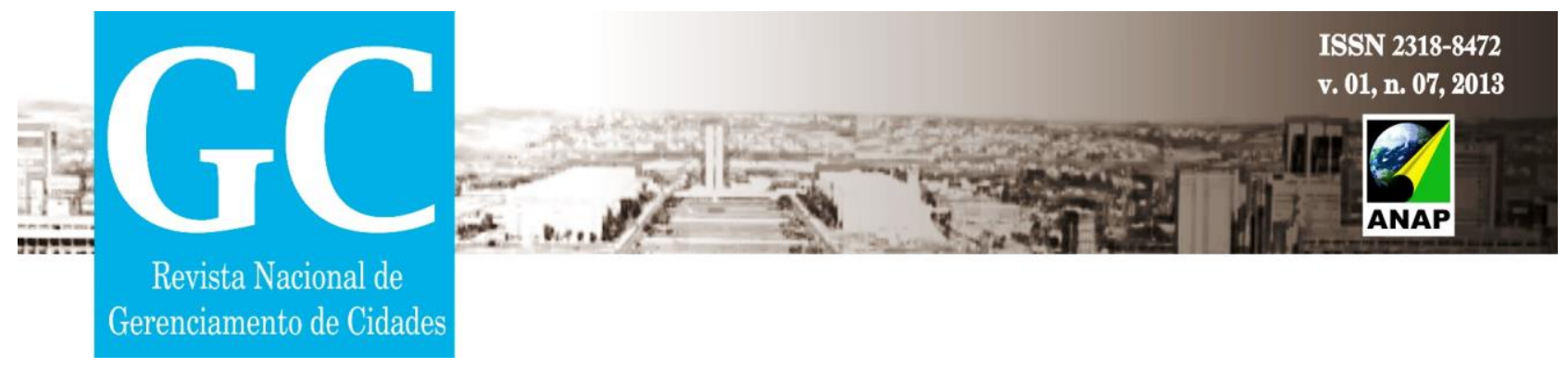

PEREIRA, 2007) (fig.04). Serra viveu a glória nos tempos de cidade privativa e diferente de Brasília, perde muito em termos de estrutura na fase Pós-Icomi, que encerrou suas atividades, deixando um "fantasma", o que foi amenizado pelo fato de alguns funcionários permanecerem no local, vinculados a um passado.

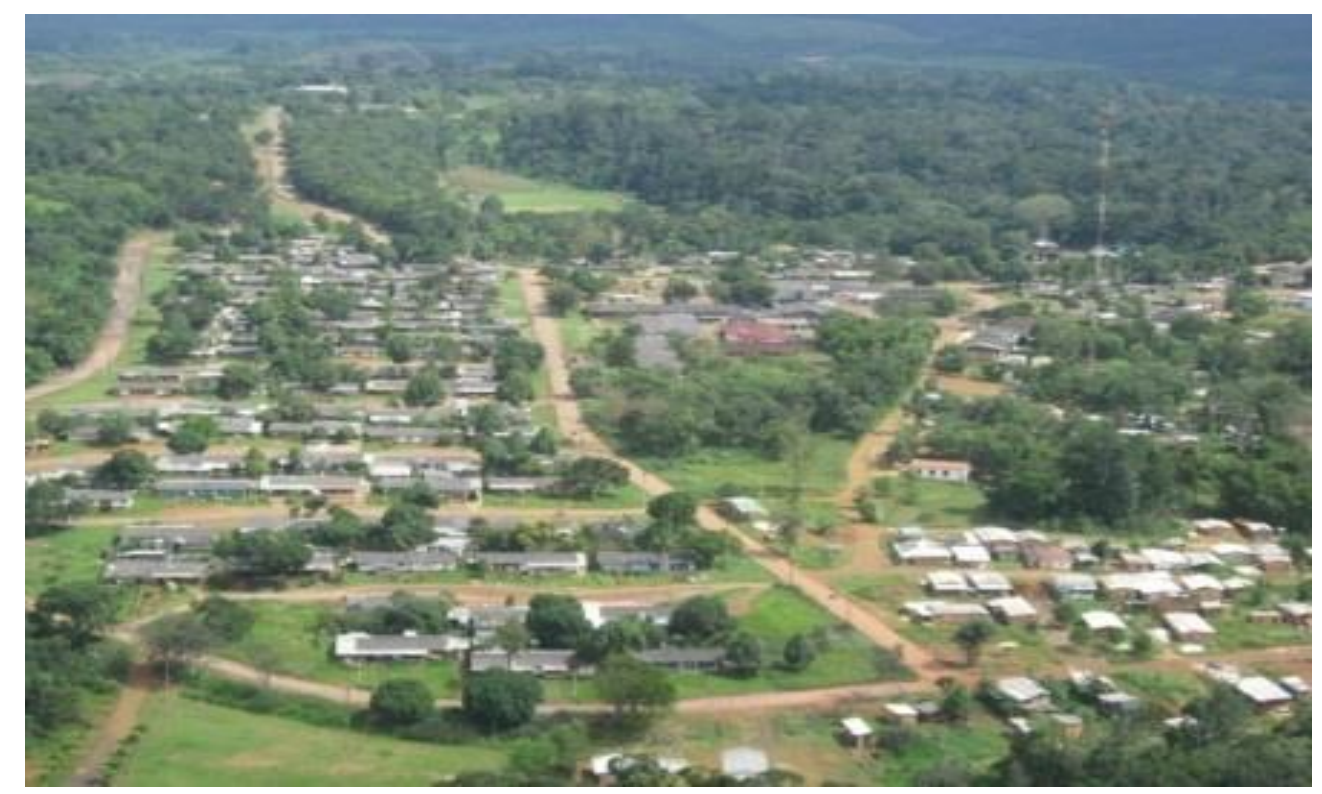

Fig. 04. Vista aérea da cidade de Serra do Navio.

Fonte: Prefeitura municipal de Serra do Navio, 2010.

No que se refere à natureza do interesse, as cidades também tiveram diferenças. Brasília atenderia a um interesse público (ser a nova capital brasileira) e Serra do Navio a um interesse privado (extensão da mineradora ICOMI), isso imprime diferenças nos projetos. Por muito tempo Serra do Navio foi mantida pela empresa, o tempo de ação nos projetos privados é muito mais rápido quando comparado ao publico onde qualquer tipo de intervenção é motivo para licitações análises e planejamento orçamentário.

A linha do modernismo em que cada cidade foi concebida é distinta. Brasília, pensada sob uma ótica do modernismo formalista e Serra do Navio, por sua vez, tem o modernismo naturalista como fonte de inspiração. O traçado das cidades é peculiar, com 


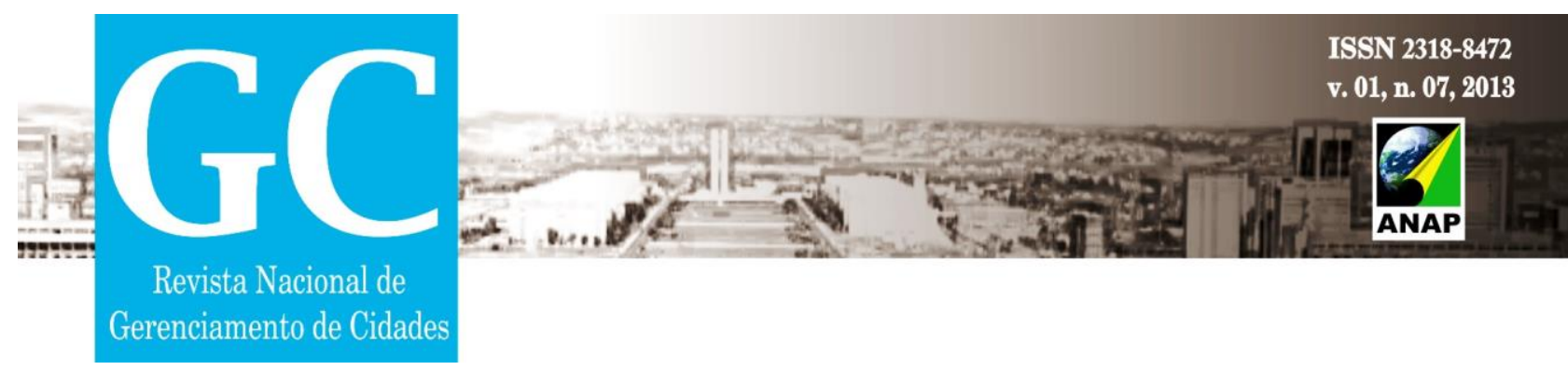

formatos singulares e diferenciados o que traduz a concepção de cada arquiteto. Independente da escala que cada uma possui, ambas tem como princípio a logicidade e o rigor do traçado urbano e a conjunção das formas arquitetônicas monumentais ou não. No caso de Brasília, a monumentalidade de seus edifícios dialoga com seu traçado em forma de avião em que no seu eixo encontram-se boa parte de seus espaços públicos e nas azas as áreas residenciais e comerciais.

Em Serra do Navio, observa-se que ao contrario de Brasília não se encontram edifícios monumentais, no entanto o arquiteto a concebe com "um traçado em forma de colher" valorizando a configuração do terreno. Este traçado é estruturado seguindo um núcleo linear e distendido que reúne e ordena todas as edificações e atividades de interesse coletivo, além de associar, com áreas verdes urbanizadas, dois afastados setores habitacionais.

A concisão parece ter sido alcançada com remanejamento posterior, quando o setor esportivo faz a ligação dos dois grupos de moradia. Em oposição a essa espinha dorsal e estrutural acusada pelo gentil caminho para pedestres, há setores envolventes recortados ora por vias locais, ora por cul-de-sacs que concentram segundo duas classes funcionais, as categorias residenciais e unifamiliares dos funcionários. O sistema viário, sempre externo, é o escudo, garante o afastamento da floresta e está complementado pela trilha interna de pedestres que cumpre a ligação retilínea e econômica entre setores.

A arquitetura das cidades se destaca pelo uso de parâmetros modernos salvaguardados as suas distinções referente adaptação climática. No que se referem às diferenças nas concepções arquitetônicas, essas sim, estão principalmente relacionadas à escala e o tipo de material utilizado.

Brasília chama atenção para sua arquitetura monumental, localizada principalmente no seu eixo central, que ultrapassa em muito a escala humana, a beleza e a plasticidade concebidas por Oscar Niemeyer dão a Brasília importância mundial como laboratório da arquitetura moderna, os materiais utilizados para gerar esta plasticidade foi 


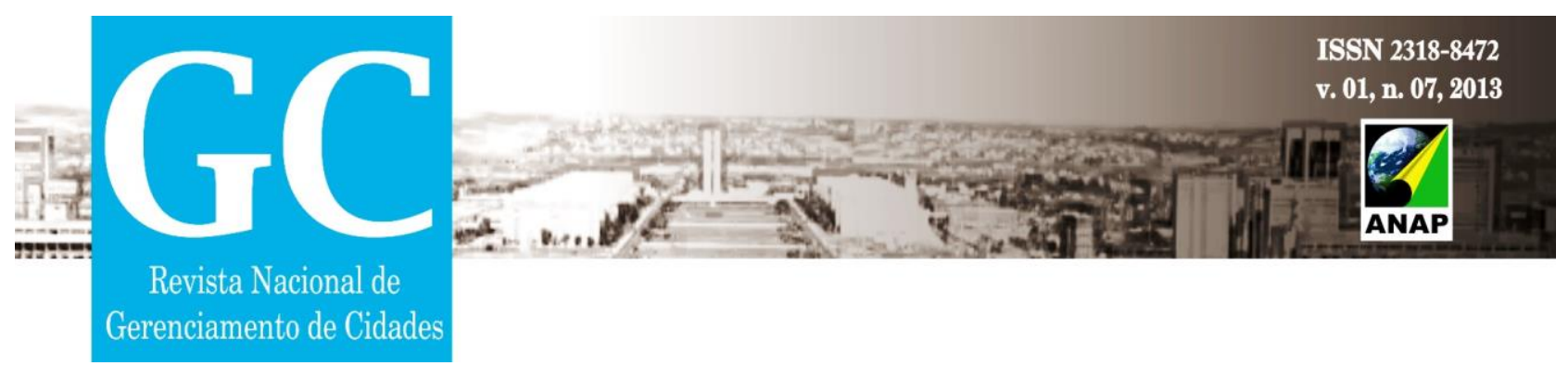

o concreto armado que na época ainda era uma novidade em boa parte das cidades brasileiras. $\mathrm{Na}$ (fig.05) pode-se observar com mais atenção o perfil de cada traçado.

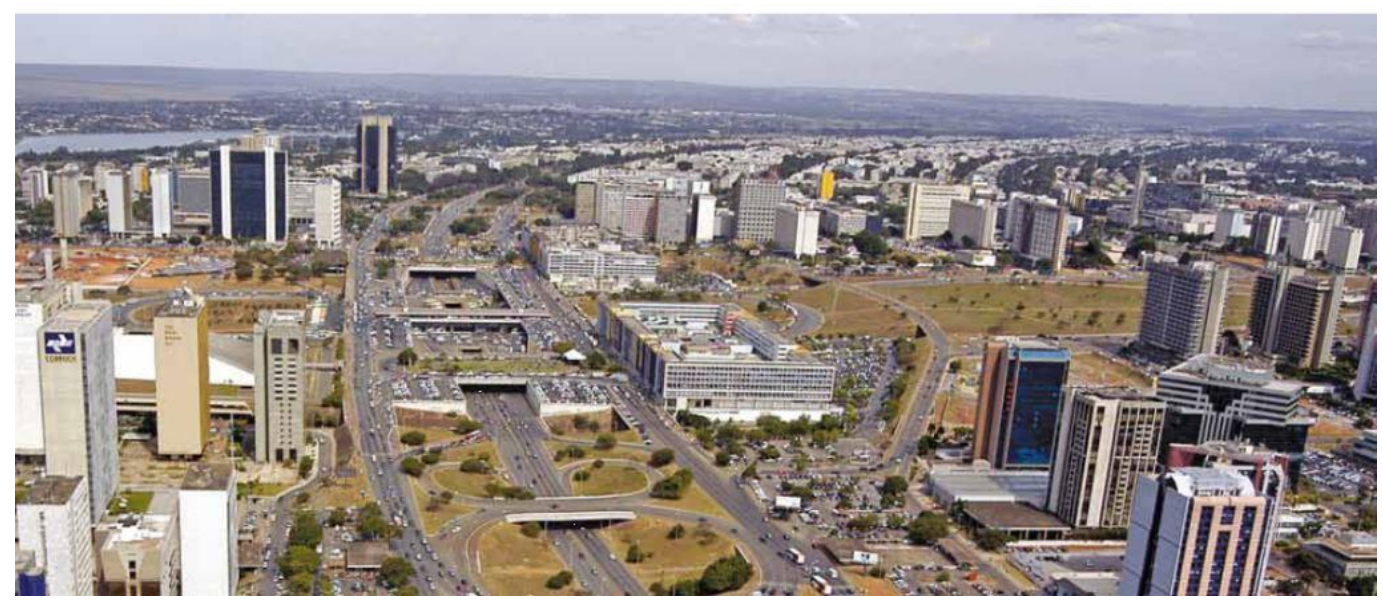

Fig. 05. Sistema viário da cidade de Brasília.

Fonte: Redes de Infraestrutura. SEDUH, Estudo dos vazios urbanos no Distrito Federal, 2006.

A arquitetura de Serra do Navio não se observa a monumentalidade dado a natureza do projeto, foi fruto de exaustivos estudos de conforto térmico e lumínico por parte do arquiteto. A escala é andrométrica e se integra ao rico meio natural ao qual está inserido. Quem visita a cidade tem a impressão de estar em uma pequena vila norte americana. Devido ao local de implantação ser distante de um centro urbano, houve grandes dificuldades na utilização de materiais, a solução foi improvisar. Segundo Segawa (1997, p. 196) a seleção dos materiais e sistemas construtivos derivou de uma racional e criteriosa análise de variáveis empíricas e econômicas. Assim:

Embora reconhecendo as deficiências dos blocos de concreto e do fibrocimento enquanto isolantes térmicos eram as únicas alternativas viáveis. Mesmo o concreto armado era um sistema fora do alcance [...] As estruturas foram todas desenhadas explorando o potencial da madeira. (SEGAWA, 1997, p. 196). 


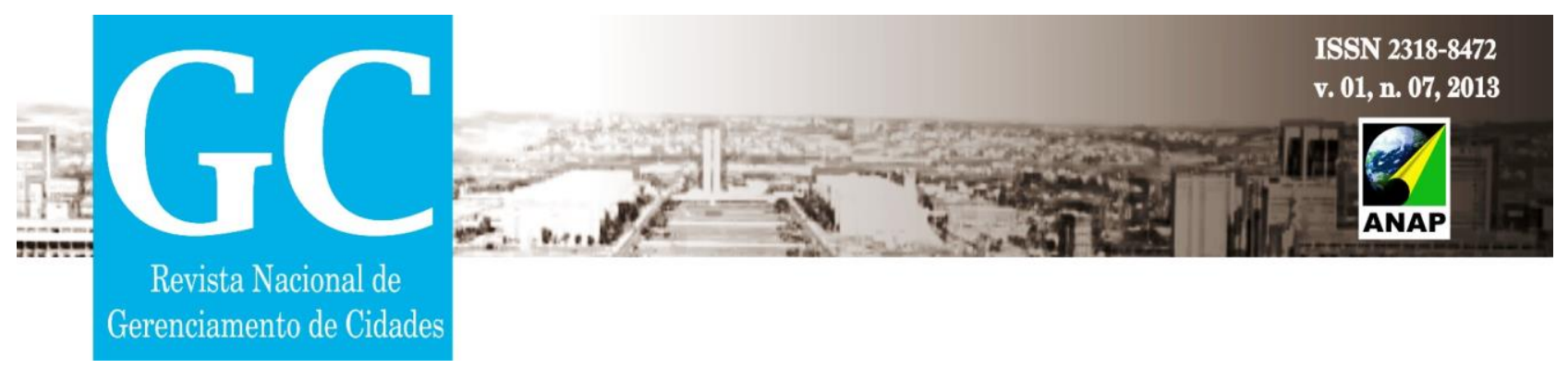

A forma como os projetistas tratam as áreas de expansão também forma díspares, embora atualmente ambas estejam sofrendo, obedecendo à proporcionalidade, a mesma configuração. No plano piloto de Brasília as áreas de expansão foram denominadas de cidades satélites, e foram locadas distante do centro. Essas distâncias, hoje sabemos, ajudou sobremaneira a preservar a estrutura do centro não permitindo sua descaracterização. Segundo Holanda (2010, p. 48).

[...] desde o princípio, forma-se uma estrutura dicotômica entre o núcleo central, objeto do concurso vencido por Lucio Costa em 1957, e uma constelação de núcleos periféricos em todas as direções, antes mesmo de inaugurada a cidade, separados do núcleo central por grandes distâncias. (HOLANDA, 2010, p. 48).

Bratke, diferente de Lucio Costa, dispõe no projeto uma grande área de expansão a ser incluída no planejamento, de acordo com pedido da ICOMI. Foram providenciadas em quadras adicionais previstas dentro do traçado viário, no setor de bairro residencial destinado aos funcionários de permanência temporária, a expansão foi prevista dentro dos lotes, omitindo a construção de edificações para sua posterior ocupação. (Ribeiro, 1992, p.56). Embora tal área tenha sito planejada, vem ocorrendo uma ocupação desordenada nas proximidades da cidade, semelhante a um processo de favelização. Um ponto em comum entre os projetos é o estimulo a baixa densidade. Tanto em Brasília como em Serra do Navio, observamos o predomínio de amplas áreas verdes e uma distância considerável entre as residências e entre os elementos do espaço público. Essa decisão contribui para o conforto térmico, pois aumenta a distância de possíveis barreiras. No entanto em alguns casos a baixa densidade causa fragmentação espacial, como é o caso de Brasília.

\section{CARACTERÍSTICAS ENTRE AS CIDADES DE BRASÍLIA E SERRA DO NAVIO}




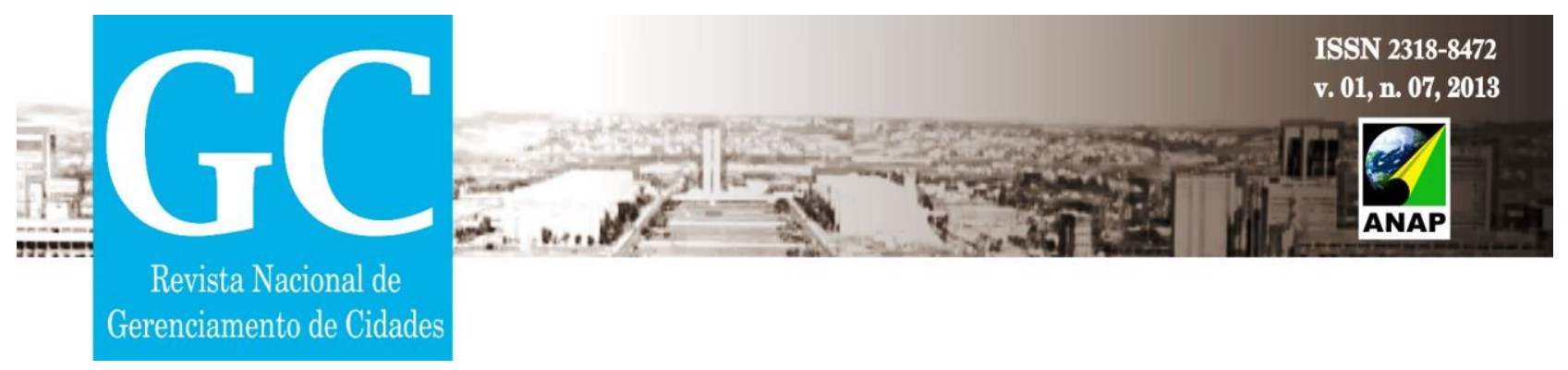

\begin{tabular}{|c|c|}
\hline BRASÍLIA & SERRA DO NAVIO \\
\hline Inauguração: 1960 & Inauguração: 1960 \\
\hline Escala macro & Escala micro \\
\hline Objetivo: idealizada para ser a capital da & Objetivo: idealizada para abrigar os funcionários da \\
República & Ambiente: Floresta tropical brasileira \\
\hline Ambiente: cerrado brasileiro & Interesse: Privado \\
\hline Interesse: público & Tipo de modernismo: modernismo naturalista \\
\hline Tipo de modernismo: modernismo formalista & Forma do traçado: Colher \\
\hline Forma do traçado: Avião & Tipo de arquitetura: andrométrica \\
\hline Tipo de arquitetura: monumental & Escala urbana: homem \\
\hline Escala urbana: veículo & Ainda não consagrada \\
\hline Consagrada pela história & Fragmentação hierárquica \\
\hline Fragmentação espacial & Fe expansão próxima do centro \\
\hline
\end{tabular}

Quadro 01. Características das cidades de Brasília e Serra do Navio Fonte: Beltrão \& Santos, 2011.

A fragmentação de Brasília se justifica pelo seu tecido urbano descontínuo na qual, as diversidades das partes somam-se vazios a separá-los. Segundo Holanda (2010, p.51).

[...] Os macroelementos estruturadores (Eixo Monumental, Eixo Rodoviário) e as longas vias vazam a cidade de norte a sul e de leste a oeste. No conjunto, a mobilidade e a apreensão global do plano são facilitadas. Entretanto, ambas são prejudicadas na escala menor, dado o intricado desenho do sistema viário no interior dos setores - superquadras. residenciais ou outros. Sistema em árvore (ruas vão se bifurcando até pontos finais dos quais temos de voltar) e muitas dobras no percurso dificultam o movimento e o encontro de um endereço." (HOLANDA, 2010, p. 51). 


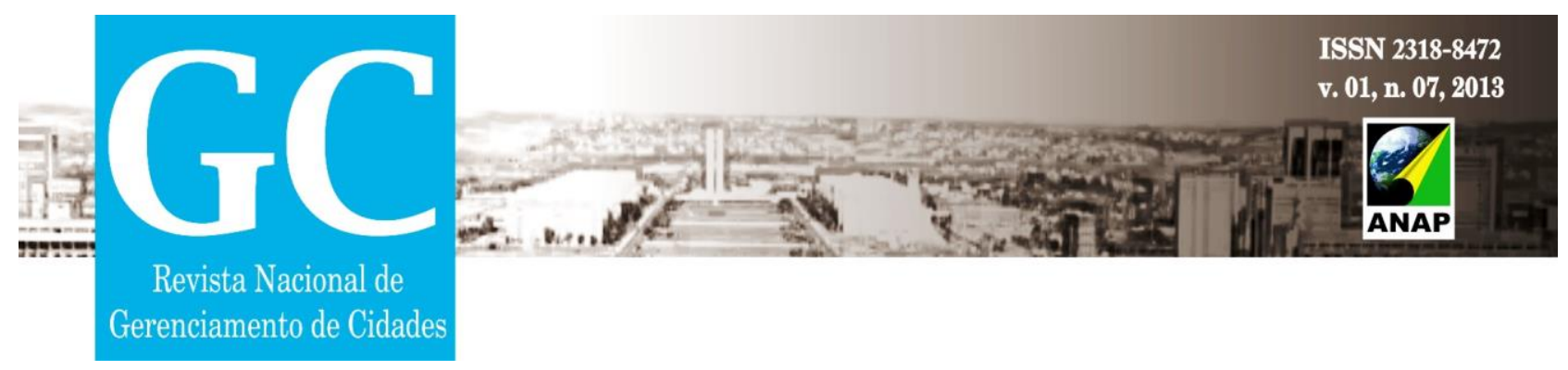

O Quadro 01 resume sistematicamente as principais diferenças entre Brasília e Serra do Navio relacionado tudo o que foi exposto acima. Com este comparativo podemos observar como o modernismo na arquitetura se adapta a diferentes realidades, por mais dispares que possam parecer.

Lúcio Costa filia-se à tradição de uma cidade bipartida matriz/satélites. Defende a clara legibilidade de seu projeto mediante isolamento físico, limites ao crescimento e manutenção da configuração do plano como testemunho do próprio urbanista: "A Brasília não interessa ser grande metrópole (...). Brasília é a expressão de um determinado conceito urbanístico tem filiação certa, não é uma cidade bastarda" (Holanda, 2010, p.48).

Outro elemento que contribui para baixa densidade em Brasília é a arborização das superquadras e dos espaços monumentais o que autor Holanda (2010, p.51) chama de "tonalidade bucólica do Plano Piloto". Este elemento combinado com os espaços residuais sem uso definido e a grande superfície do sistema viário projetado para o automóvel excedem as necessidades funcionais e ambientais.

Em Serra do Navio, também ocorre uma fragmentação. Porém diferente de Brasília, esta é advinda do planejamento hierárquico do projeto. Temos, assim, separação no que se refere ao padrão habitacional em diversos setores todos ligado a um centro comercial. Fora do projeto, atualmente, observamos uma fragmentação parecida com a de Brasília, onde as novas periferias estão distantes do núcleo do projeto original, obedecendo a um padrão bem diferente com relação à vila de Serra do Navio.

\section{CONSIDERAÇÕES FINAIS}

Brasília e Serra do Navio foram inauguradas quase na mesma época, hoje com pouco mais 50 anos, observa-se poucos cuidados com relação a Serra do Navio. Brasília segundo Tostes (2011), "está consagrada na História da Arquitetura e do Urbanismo, Serra do Navio, precisa ser inicialmente consagrada pelo povo amazônida e 


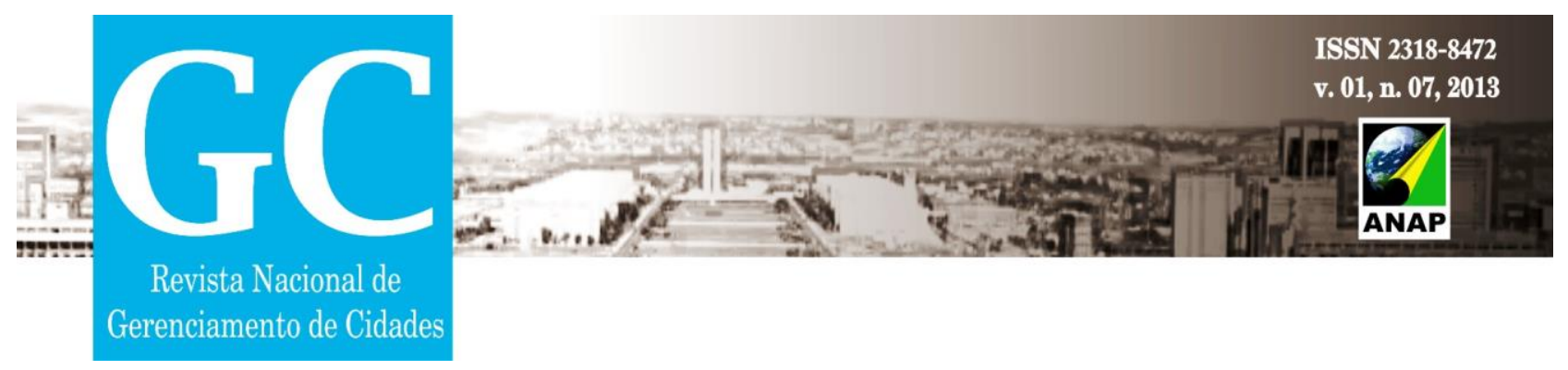

principalmente pelos amapaenses". Ambos os projetos tiveram argumentos políticos institucionais. Brasília configurada no discurso desenvolvimentista, enquanto que o projeto de Serra do Navio visava a exploração de riquezas minerais na Amazônia, com o projeto de Serra do Navio, iniciava-se um conjunto de cidades planejadas na região sob a tutela do discurso da ocupação territorial. As escalas são distintas, mas os objetivos delineados nestes projetos evidenciam a diversidade com que os arquitetos Oswaldo Bratke, Lúcio Costa e Oscar Niemayer colocaram em tela, condições morfológicas em áreas bastante adversas, a selva amazônica e o cerrado brasileiro. As reflexões sobre Brasília e Serra do Navio apontam para duas importantes referências da arquitetura brasileira no século XX.

\section{REFERÊNCIAS}

BELTRÃO. L. SANTOS, J. Serra do Navio: o espaço público na cidade modernista na selva amazônica. Trabalho final do Curso de Arquitetura e Urbanismo. Santana. 2011.

HOLANDA, Frederico. Brasília 50 anos. FAU UnB, 2010.

DRUMMOND, José Augusto; PEREIRA, Mariângela de Araújo Póvoas. O Amapá nos tempos do manganês: um estudo sobre o desenvolvimento de um estado amazônico 1943-2000. Rio de Janeiro: Garamond, 2007.

RIBEIRO, Benjamim Adiron. Vila Serra do Navio: comunidade urbana na selva amazônica: um projeto do arq. Oswaldo Arthur Bratke. São Paulo: Pini, 1992.

SCHLEE, A.R \& FICHER, S. Prefácio do livro Brasília - Cidade moderna, cidade eterna. Brasília. 2010. 


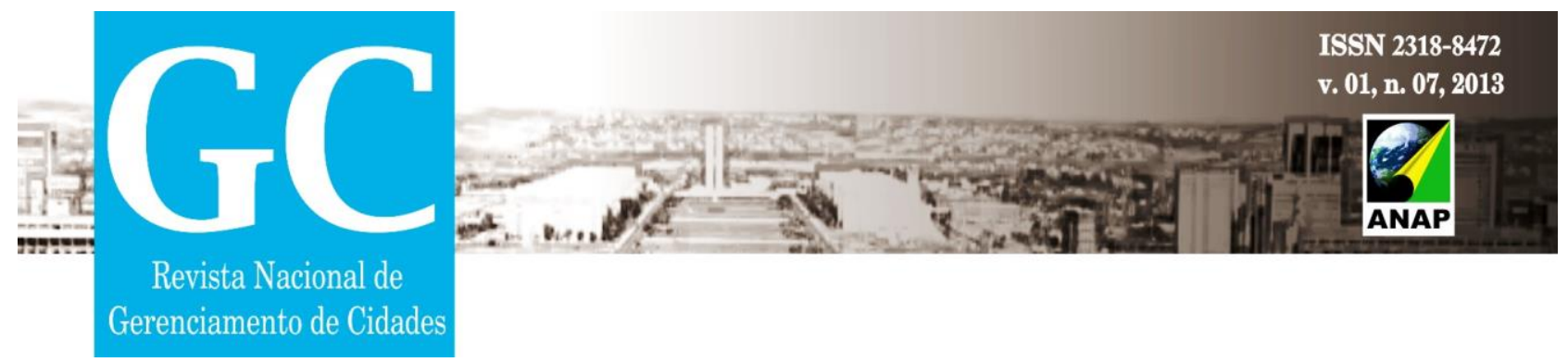

SEGAWA, Hugo; DOURADO, Guilherme Mazza. Oswald Arthur Bratke. São Paulo: Pro Editores, 1997.

TOSTES, J. A. Do público ao privado: A concepção das cidades de Serra do Navio e Brasília - Artigo publicado no dia 14 de maio de 2011 no Jornal A Tribuna Amapaense.

Espaço Público e Espaço Privado - Artigo publicado dia 21 de maio de 2011 no Jornal Tribuna Amapaense. 